\title{
Building Better Ecological Machines: Complexity Theory and Alternative Economic Models
}

\author{
JESS BIER \\ ERASMUS UNIVERSITY ROTTERDAM \\ WILLEM SCHINKEL \\ ERASMUS UNIVERSITY ROTTERDAM
}

\begin{abstract}
Computer models of the economy are regularly used to predict economic phenomena and set financial policy. However, the conventional macroeconomic models are currently being reimagined after they failed to foresee the current economic crisis, the outlines of which began to be understood only in 2007-2008. In this article we analyze the most prominent of this reimagining: Agent-Based models (ABMs). ABMs are an influential alternative to standard economic models, and they are one focus of complexity theory, a discipline that is a more open successor to the conventional chaos and fractal modeling of the 1990s. The modelers who create ABMs claim that their models depict markets as ecologies, and that they are more responsive than conventional models that depict markets as machines. We challenge this presentation, arguing instead that recent modeling efforts amount to the creation of models as ecological machines. Our paper aims to contribute to an understanding of the organizing metaphors of macroeconomic models, which we argue is relevant conceptually and politically, e.g., when models are used for regulatory purposes.
\end{abstract}

\section{Keywords}

complexity; modeling; macroeconomics; machine; ecology; emergence; crisis

\section{Introduction}

"The universe is not a computer." This is the title of a recent paper by the physicist Ken Wharton (2013), who counters one dominant view in the natural sciences, namely, that the universe can be conceived of as an enormous data processer. ${ }^{3}$ The belief that the world is one large machine has a

Jess Bier, Email: bier@fsw.eur.nl

2Willem Schinkel, Email: schinkel@fsw.eur.nl

${ }^{3}$ The authors thank the editors and the anonymous reviewers of Engaging Science, Technology, and Society, as well as the researchers and affiliates of the Monitoring Modernity group. Jess Bier would like to thank Jayne Debattista, her family, and the participants of the Netherlands Graduate Research School for Science, Copyright (C) 2016 (Jess Bier and Willem Schinkel). Licensed under the Creative Commons Attribution Noncommercial No Derivatives (by-nc-nd). Available at estsjournal.org. 
long history, and it has been applied to universes, organisms, and quantum matter. Alan Turing once quipped that humans were, if not machines, then mere data repositories: "I think of people as pink-coloured collections of sense-data" (as quoted in Hodges 2012, 137). For his part, Wharton argues (2013) that the computer metaphor is unworkable. The assumption that the universe operates like one large computer, Wharton asserts, confuses methods of knowing the universe with the entirety of the universe itself. Just because the universe may be called a universe, the universe can't be reduced to the word "universe." Just because it may be possible to make calculations in order to understand the universe, that doesn't mean that the universe is reducible to the numbers that are used to do so.

Astrophysics is hardly the only academic discipline in which systems are readily compared to computers and machines. In the writings of economists, machine metaphors crop up repeatedly, particularly as economic modeling has come to take an increasingly prominent role in the discipline. Yet, while an understanding of the organizing metaphors of macroeconomic models appears relevant for an assessment of their potential uses, such metaphors are rarely scrutinized. Notable exceptions can be found in the sociology and anthropology of economics, which remain undervalued within economics itself (e.g. Evans 2002; Knorr Cetina and Preda 2005; MacKenzie 2006; Pinch and Swedberg 2008; Zaloom 2006; Zelizer 1994).s One of the contributions of historical, sociological and anthropological studies of economics is that the heuristic and performative effects of the organizing metaphors of economic theories and models have been highlighted (Maas et al. 2011). In this sense, metaphors like computer and machine are part of larger imaginaries that shape how markets and economies are perceived by those who study and intervene in them. For Sally Wyatt, metaphors "can be used to help the imaginary become real or true" (Wyatt 2004, 244) in the ways markets are performed and produced. As such, imaginaries are tremendously influential in terms of what is considered to be probable, possible, and even natural to an economy and to society more broadly. If conceiving of the universe as a computer risks reducing the universe to a series of calculations, then, depending on one's conception of a machine, "imagining an economy as a machine suggests that economic decisions are rational and knowable. In the process, it threatens to excise entire constellations of emotions, motivations, and experiences.

Technology, and Modern Culture (WTMC) 2015 postdoctoral day, including Sally Wyatt, Marijke Hermans, and Alex Rushforth. This research is part of the Monitoring Modernity project and was supported by an ERC Starting Researcher Grant by the European Research Council under grant number 283679.

"For a critique of the notion that the brain is a computer, see Barrett (2015).

s Graeber (2012) is presently one of the most well-known anthropological accounts of economics. See Caldararo (2014) for an explicit exploration of complex economic systems and a call to study "ecological foundations." Both books differ widely from computational complexity because they drawing extensively on literatures in the history and anthropology of economics. In addition to these anthropological sources, there has also been some debate in geography about the compatibility between political economy and complexity theory (Jessop and Sum 2010; Van Heur 2010b; 2010a).

'Historically, different conceptions of 'machine' have been operative in economics. See Wyatt (2004) for an account of economic metaphors that derive from Darwinian evolution, Newtonian mechanics, and thermodynamics. 
Yet machine metaphors are not alone in shaping the imaginaries of economic modelers, as is evident in other contemporary writings. In recent years the machine metaphor has been joined by the metaphor ecology as complexity economics has sought to move beyond machine metaphors. This metaphorical shift involves a turn to include other processes that are related to environment, evolution, emergence and contingency. The metaphor of ecologies is presented as an alternative to the metaphor of machines and is meant to better capture the world and the economic activity that occurs within it; they are used regularly as metaphors by the modelers themselves and are, therefore, prominent in the recent literature on macroeconomic modeling.

In this article, we explore the organizing metaphors of the two predominant types of macroeconomic models. Through an analysis of both conventional macro-economic models (e.g., Dynamic Stochastic General Equilibrium models or DSGEs) and more recent complexity models in economics (Agent Based Models or ABMs), we explore modelers' imaginations of DSGE models as machines, and complexity models as ecologies. In the recent literature, both ecology and emergence (associated with ABMs) are often presented as if they were opposed to, and separate from, machine logics (associated with DSGEs). In contrast, we show that complexity models remain wedded to machine logics at crucial points. So, while often pitted against each other in terms of "machine" versus "ecology," we examine recent modeling efforts and argue that the notion of an ecological machine might in fact be more helpful for understanding current macroeconomic modeling. We conclude by tentatively illustrating that this confluence, where machines and ecologies unexpectedly overlap, constitutes a form of cyborg imagination, which may open up an as yet untapped potential for incorporating the heterogeneity of economic (f)actors into economic models.

In what follows, we first briefly discuss the role of machine and ecology metaphors in, respectively, DSGE and ABM models. We then turn to the most commonly-used policy models, the DSGE models, and use an iconic ABM, the Schelling segregation model (Sethi 2015), to explain the differences between ABMs and the currently dominant DSGE approach. After embedding our analysis in a historical overview of machine and ecology metaphors, we proceed to compare two ABMs, the metaphors by which they are described by the modelers themselves, and the imaginations of economy and society that they invoke.

Although designed to explain a specific type of social segregation, the Schelling model serves as a readily accessible forerunner of many complexity models of the economy. After laying out the overall approach of ABMs, we proceed to analyze two aspects of EURACE, a current policy-relevant ABM model. EURACE demonstrates the new aspects of notions like emergence and ecology while also examining the continuities between ABMs and more traditional models. EURACE is intended as a complexity alternative to DSGE models, and as a complexity model it is based on the complexity view of the economy as an ecology. However, importantly, it nonetheless incorporates aspects of the view of the economy as a machine. We conclude by drawing on Haraway's (2000) figure of the cyborg to discuss the ways in which models are hybrids, what we call ecological machines. First, however, we explore the historical legacies that have shaped present notions of machine, organism, and ecology. 


\section{The Machine Metaphor in DSGE Models}

At times modelers have used the machine metaphor quite literally. In the 1950s and 1960s, prior to the widespread advent of computers models, economists even built physical machines as models of national economies. For decades courses in macroeconomy were routinely taught using machines called MONIAC or Phillips models. The precursors of computer models, the MONIAC and Phillips models were actual (analogue) machines: transparent boxes of levers, pumps, and tanks the size of a refrigerator. These machines worked by forcing flows of colored water (currency) from boxes marked "national savings" into boxes marked "investment." They were readily adapted to computer models in the 1970s and 1980s, as MONIAC became FYSIOEN, a computer model that displayed graphics on a computer screen. Yet the graphics were not pictures of a national economy, whatever that might mean. The images were representations of a MONIAC. In this way, the physical machine models of the 1960s were incorporated into digital models on a computer (see Figures 1a and 1b) (Boumans 2012; Kramer et al. 1990; M. S. Morgan 2012; M. S. Morgan and Boumans 2004).

In contemporary economics, the economy is modeled primarily on computers, but in ways that are rarely visually linked to such predecessors, and which are more likely to output charts, graphs, and tables of numbers. This is the case with the most common group of standard policy models, Dynamic Stochastic General Equilibrium (DSGE) models, which rest on neoclassical theory but with selected modifications to make them more relevant to contemporary economies.

This borrowing of machine metaphors affects fundamental questions of economics. It cordons off "economies" as separate realms-whereas the notion of "an economy" as a bounded object has emerged only in the early $20^{\text {t }}$ century, as Mitchell (2002) has argued. It also assumes that such bounded wholes consist of mechanically interrelated parts and thus gives credibility to notions of individual utility and preference that were solidified in $20^{\text {th }}$ century quantitative economics. DSGE models are infamous because they largely failed to predict the onset of the 2008 economic crisis. As such, they have become associated with an overly narrow view of the world that predominates in mainstream economics. In their written work, DSGE modelers repeatedly invoke the notion of machines. In contrast, the term ecology and its associated characteristics predominate in the literature on complexity economics, which is often presented as a corrective to DSGE modeling. For example, one paper by three prominent ecologists, entitled "Complex Systems: Ecology for Bankers" (2008), seeks to convince bankers of the value of looking beyond traditional models and turning to ecology. 


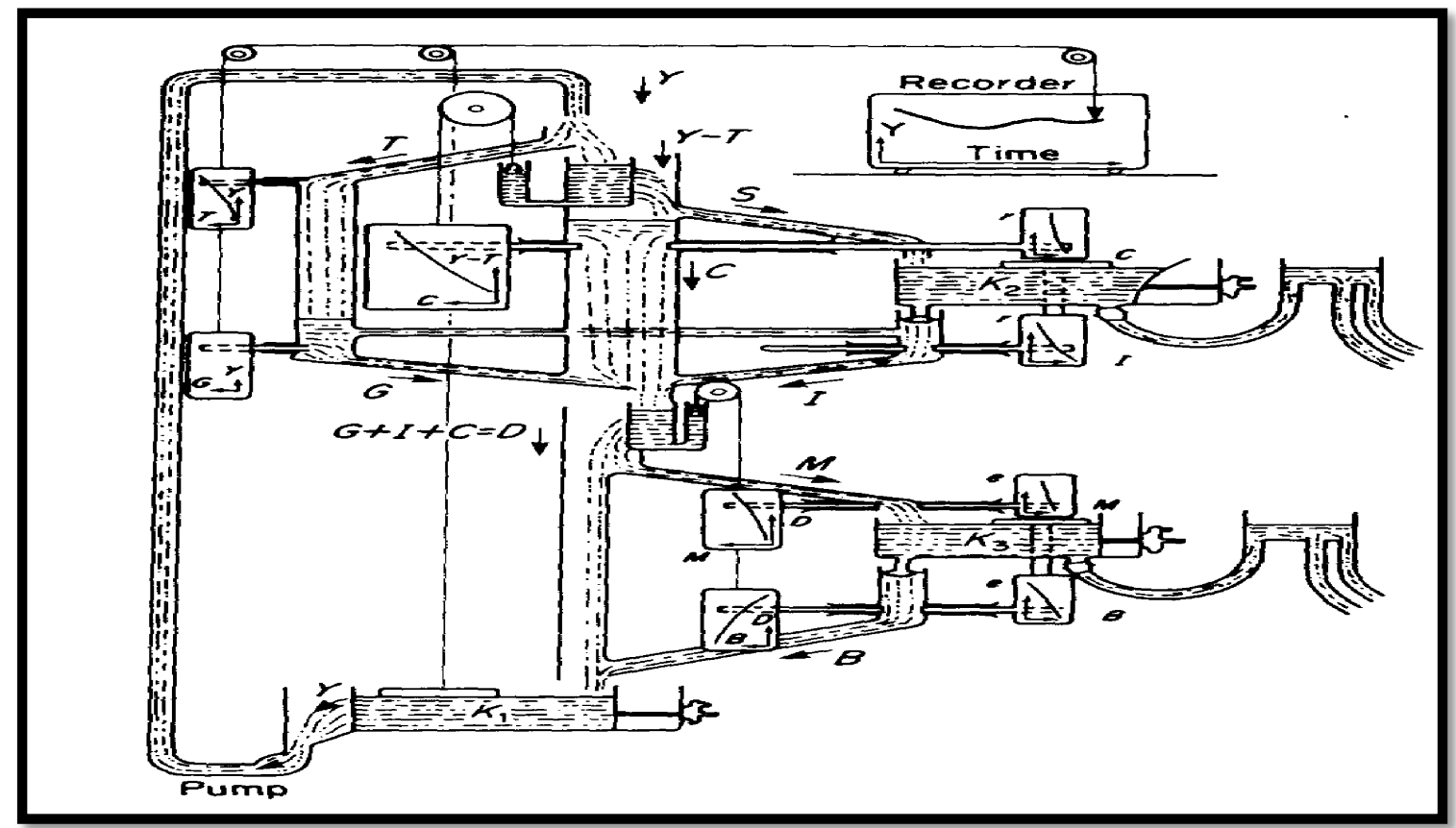

Figure 1a: Image of one Phillips or MONIAC machine, an attempt to build a physical model of a national economy.

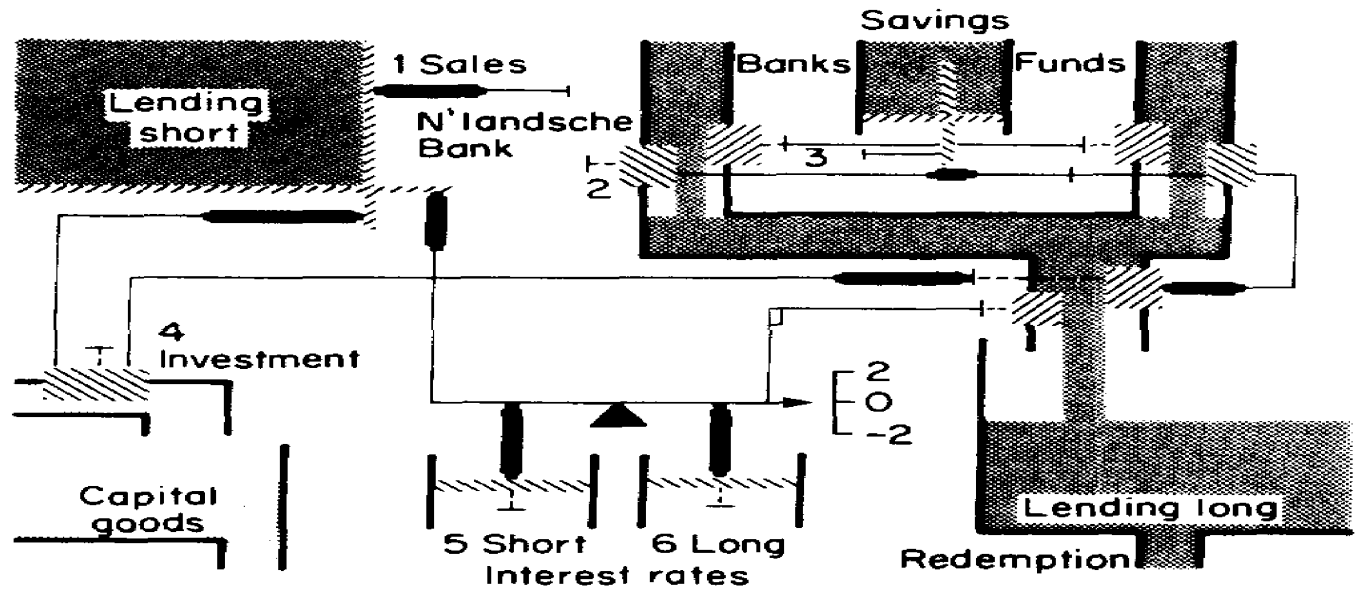

Figure 8. Bank lending.

Figure 1b: Image of one part of the larger FYSIOEN model, a computer model that directly copied the MONIAC structure but translated it into a digital form. Source: (Kramer et al. 1990, 150, 155). 
Similarly, Brian Arthur (2013) has claimed that the complexity view is more relevant to the contemporary economy, in that it "gives us a world closer to that of political economy than to neoclassical theory, a world that is organic, evolutionary, and contingent." We now turn to ABM models as ostensible ecological alternatives to the machinic DSGE models.

\section{The Ecology Metaphor in ABM Models}

Within economics, debates over the multiplicity of the economy have become more textured in recent years, as new metaphors like ecology have accompanied the transformations from analogue machines, to images of analogue machines, to computer simulations that arose out of these earlier practices but which are also somehow different. Similarly, the idea of humans as machines has not been discarded. In an echo of Turing's comment about "pink-coloured collections," Church and Waclawski (1998) have argued that, "Although we may not like to think of ourselves as a collection of specific data points just waiting to be identified, gathered and quantified in some controlled fashion, in large part that is what we in fact are."

Not all presentations of this transformation are similarly reductive. Several of the more compelling examples come from complexity theory, where researchers have claimed that the economy emerges from diverse micro-scale practices in such a way that "the whole is more than the sum of its parts" (Phillips 1970, 413). As one aspect of an effort to better understand key tenets of the early 21 " century-including randomness, unpredictability, risk, and vulnerabilitycomplexity theory, and its predecessor chaos theory, can be seen as a search to provide scientific solutions to central problems of science and society. However, it is a heterogeneous science given that the notion of complexity is notoriously difficult to pin down, encompassing colloquial, scientific, and social theoretical definitions (Law and Mol 2002; Holland and Page 2007).

In designing economic applications, many complexity theorists work with agent-based models (ABMs) (e.g. Agar 2005; Ballot, Mandel, and Vignes 2014; Buchanan 2009; Cogliano and Jiang 2014; Farmer and Foley 2009; Li 2013). ABMs allow for the study of how macro-scale patterns develop from thousands or millions of interactions of heterogeneous micro-scale agents, instead of modeling the economy through a series of aggregate equations that may or may not be founded on micro data. In so doing, and in contrast to depictions of the economy as a machine, complexity theorists posit that the economy constitutes an ecology (Arthur 2013, 7). They thereby borrow from literature on ecologies that incorporates both natural science and social theory and whose influence in economics stretches back at least to the 19" century (Simpson 2013). In a seeming paradox, the most recent turn to ecology is intimately associated with the rise of computers, as noted in 1970 by the well-known ecologist Max Nicholson, who claimed that, due to their ability to handle complex methods, "the computer age will compel ecology, in spite of the ecologists, to assume a central role" in the social and economic management of the Earth,

- Phelan (2001) distinguishes between complexity science and broader complexity theory, in an attempt to more clearly delineate the boundaries of complexity science. 
including "economy principles already tested in ecology, and computer-born opportunities" $(1970,281-84)$.

Through their call to ecology, complexity models of the economy both draw on and serve to correct central tenets of economics, including causality, stability, and equilibrium. In order to better understand to what extent complexity models represent an alternative approach, here we tease out the similarities and differences between complexity and mainstream macroeconomic models. We show how notions of emergence and ecology grew out of, but differ from, the more common focus on the economy as a machine in equilibrium. This machine-equilibrium focus is retained overall in macroeconomic models, even in the modified approach present in the DSGE models, which were heavily criticized for failing to predict the onset of the present economic crisis (Hendry and Mizon 2015; Subcommittee on Oversight 2010). However, the prevalence of machine and ecology metaphors is not necessarily a detriment. Instead, greater diversity in the imagination of both machine and ecology are needed. In order to fully illustrate the import of notions of ecology, we now first discuss the rise of this concept and its links to the concept of emergence.

\section{Ecology and Emergence}

Although ecology is often presented as a recent notion in the literature on complexity models, the term itself dates back 150 years. The concept of ecology was coined by Ernest Haeckel in his Generelle Morphologie. Haeckel mentions it almost in passing, to denote both "geography" and the "physiology of the relations between the organism to the world outside" (1866, I: 237). However, he also describes "ecology" as "the science of the interrelations between organisms" (Haeckel 1866, II: 236). Its use needs to be considered in the context of $19^{\text {in }}$ century biology as entailing a shift towards a more contextual and holistic paradigm (Bramwell 1989, 39-40). In Haeckel's wake, "ecology" came to focus attention on the entire web of relations between organisms and their environment. Also, for Haeckel the concept of ecology signifies a shift away from a more mechanistic conception of living beings. ${ }^{.}$Over and against a notion of the rigid boundaries of organisms, the concept of ecology places the extension of organisms in their mutual environments, and it displaces the "boundaries" in question to the boundaries of the entire ecology. Since an ecology was seen to consist of a set of relations, it could be considered as a system itself. This was expressed in the concept of "ecosystem," first used by A.G. Tansley (1935) to express the unity of the system of organism and habitat at "multitudinous levels."

The re-emergence of organicism as a dominant discourse in the $19^{\text {in }}$ century forms the backdrop of the concepts of ecology and ecosystem.. Organicism appeared as a more holistic conception that could better explain a wide range of phenomena observed but unexplained by the mechanicism of the $16^{\text {in }}$ to the $18^{\text {in }}$ century. Magnetism was one case in which mechanicism failed to provide convincing accounts, and to consider electro-magnetic fields as systems of

s Politically, Haeckel's conception of ecology was enormously influential and by no means benign (Sommerey 2015). This illustrates how the notion of ecology alone is not somehow more naturally predisposed towards the creation of more politically progressive or open models. 
relations extended across a space and time meant a decisive break with what the historian of science Dijksterhuis famously called the "mechanization of the world-view" (1975). This heyday of organicist thought across a variety of scientific disciplines, and extending into philosophy, medicine and art and literature, laid the foundations for Haeckel's conception of "ecology." For the development of that concept and its difference vis-à-vis the concept of machine, the relation between parts and whole is crucial.

Parts, Whole and Emergence

Organicism is a precursor to complex systems theory in terms of its holistic approach (Sawyer 2005), but also in the sense that its emphasis on "organisms" implies a focus on "organization." In Darwin's Origin of Species, "organism" is for instance defined as "an organized being" $(1968,472)$. But it is important to note that it has this in common with mechanicism; organon tellingly translates as "instrument," and Raymond Williams $(1982,263)$ accordingly reminds us of the synonymous use of "mechanical" and "organical" in the 16" century. Historian of science Judith Schlanger points out that, for instance in Bonnet and Saint-Simon, mechanicism and organicism are on par insofar as the latter (organicism) also concerns the assumption of an order or organization of organisms. She even speaks of la machine organique or "the organic machine." Where organicism and mechanicism differ, however, is in their specific conception of this organization. As Karl Muenzinger wrote:

This dichotomy, organismic-mechanistic, is thus concerned with the nature of the organization of the pattern of forces in a certain process. On the one hand we have a dynamic whole determining at any time the constituent forces, while on the other hand we have a mosaic determined by the direction, intensity and place of the elementary forces. $(1935,519)$

The crucial difference between mechanicist and organicist conceptions thus lies in the relation between parts and whole. In a machine, the whole does not supersede the parts in any way. Mechanicism is thus a form of reductionism. For organicists, according to philosopher of science Ernest Nagel:

The central theme of organismic biology is that living creatures are not assemblages of tissues and organs functioning independently of one another, but are integrated structures of parts. Accordingly, living organisms must be studied as "wholes," and not as the mere "sums" of parts (1951, 328-29).

This privileging of the whole is formulated in direct opposition to models that emphasize the machine metaphor (Phillips 1970, 413).

Parts and whole are often considered as different levels or scales at which some organism, or a system more broadly, operates. That the whole is "more" than the sum of its parts is then related to emergence, which has become a key concept in complex systems theory. Most generally, emergence concerns "patterns, structures, or properties that are difficult to explain in terms of the 
system's components and their interactions" (Sawyer 2005, 4). Many versions of emergence exist in both philosophy and science. Some accounts emphasize unpredictability while others focus on the irreducibility of higher-level phenomena, and still others define emergence in terms of novelty. For instance, in his 1922 Gifford Lectures on "emergent evolution," Lloyd Morgan said:

Under what I here call emergent evolution stress is laid on this incoming of the new [....] It is beyond the wit of man to number the instances of emergence. But if nothing new emerge--if there be only regrouping of pre-existing events and nothing more--then there is no emergent evolution (1931, 1-2).

Emergence is key to complex systems theory because emergent properties are considered to be conditioned by a certain degree of complexity (Bertalanffy 1968, 55; Klir 2001, 159).

For many engaged in modeling, emphasis on emergence entails a form of antireductionism. At the same time, most start by modeling the behavior of lower-level components or parts and then work their way up. In economics, methodological individualism also prevails when the economy is conceived of as a complex system. Robert E. Lucas $(1988,5)$, while considering economies as complex systems, nonetheless writes of a "mechanics" of economic development, and of modeling as "The construction of a mechanical, artificial world, populated by the interacting robots that economics typically studies, that is capable of exhibiting behavior the gross features of which resemble those of the actual world." Similarly, Sawyer notes that despite, or perhaps because of, the focus on building models from lower-level components, the "reading of complex dynamical systems theory that one often finds in the writings of economists...[is] a reductionist, atomistic version, perhaps most explicitly demonstrated in multiagent system computer models of societies $(2005,24) . "$,

So it is indeed possible to conceive of emergence in reductionist terms. Emergence then tends to become another word for a feature of aggregate levels, as when gas pressure is considered an emergent phenomenon nonetheless completely reducible to individual gas molecules. Similarly, the influential concept of "supervenience" connotes the idea that two indistinguishable lower-level phenomena have the same upper-level characteristics, and that upper-level phenomena (called "supervenient phenomena") cannot change without changing the lower-level phenomena (cf. Kim 1984). Likewise, DSGE models presuppose at least the possibility of equilibria fully explainable by micro-phenomena (preferences of decision makers). For many economists, then, emergence is assumed to exist at aggregate or upper-level states of systems even though it is conceived in reductionist terms and thus fully retraceable to individual, lowerlevel components. The question is, what changes when complexity models are described in terms of ecologies? One possible response becomes clear through a comparison of complexity models with the mainstream DSGE approach.

- On Lucas, see also Boumans (1997). 


\section{DSGE and Segregation: From Equilibrium to Emergence}

DSGE models are wonderful [...] but they are one particular point of equilibrium that you are looking at. Then you are relating it to this world out there [...] which has this complexity, this diversity going on. And, yes, you can squeeze and push these DSGE models to make them explain things, but it is like telling people here, "yes, we can get a little roughness in the topography," when there is actually a gigantic cliff (Testimony of David Colander, Subcommittee on Oversight 2010, 48).

The quotation above comes from testimony given during a US congressional hearing on macroeconomic models in 2010. The hearing focused on the failure of DSGE models to foresee the 2008 crisis, and one of the main points of discussion was the difference between DSGE models and alternative approaches like ABMs. If the beginning of the crisis laid bare the failures of the commonly used DSGE models, it also showed how important macroeconomic models might potentially be in helping policymakers gauge systemic risks that pertain to the broader economy rather than individual companies. The financial crisis provided both the immediate cause and the broader context of the hearing, which enabled open criticism of DSGE models from even mainstream economists. Indeed, Raberto et al. (2014) have noted that the crisis has shifted the modeling agenda from one of gradual reform of DSGE models to a focus on new, albeit related, methods. Even Jean-Claude Trichet, the former head of the European Central Bank, famously called for greater attention to heterogeneity in modeling.

So the search was on to either extend or replace DSGE models with alternatives such as ABMs and other complexity models. Complexity models certainly existed before the crisis, and there were ongoing attempts to popularize them in economic circles (e.g. Beinhocker 2006; Mandelbrot and Hudson 2010). Nonetheless, the crisis provided a boost to complexity arguments, which raises the question: What are the specific differences between DSGE models and ABMs?

On the surface, the model types are similar to the extent that they are computational and use statistical software. In both types, a modeler can choose specific starting conditions like interest rates, then run the model and outputs graphs and charts that show possible future states of the economy, including things like GDP growth over time. However, in terms of the output, there are differences. For ABMs, there have been difficulties adapting model output to policy decisions, owing in no small part to the issue of calibration, or the ability to translate the numbers and patterns put out by the model into statistics that are analogous to observed statistics (Ballot, Mandel, and Vignes 2014). In contrast, DSGE models have been more successful at calibrating the models' output to numbers that can be translated into relevant units (for example, Euros), and orders, so that they more convincingly mimic observed statistics.

But there is no hard and fast boundary between DSGE and complexity models. The differences noted above are partly, if not wholly, a matter of degree. In addition, commentators end to describe the models as they are now and say little about the ultimate potentials of either model type. Indeed, DSGE models are arguably a special case of ABMs, meaning that it may be possible to create an ABM that acts like a DSGE, but that the possibilities for ABMs overall are 
much broader. This is why, in the quotation above, Colander criticizes the "little roughness" of modified DSGE's for failing to account for the occurrence of a "gigantic cliff."

Some modelers turn to concepts like learning that aim to soften the DSGE models' strict machinic assumptions. However, as Sethi points out, this is a "small step" in comparison with ABMs (2015); De Grauwe (2010) similarly notes that learning "has up to now left few traces [...] in the DSGE-models." Overall, scholars are increasingly arguing that the adaptations made so far to DSGE models are minimal compared to the possibilities of ABMs. Critics, like the historian Merijn Knibbe (2015), maintain that DSGE involves important strands of "market fundamentalism," including the assumption that education and government have no impact.

Because the differences between DSGEs and ABMs are not fixed, however, attempts to explain the distinctions are one likely reason why metaphors like machine and ecology have become so important to the ways that modelers discuss and conceive of their models. To better understand the similarities and differences between DSGEs and ABMs without relying upon notions of ecology and machine, we next explain both types of models before turning to a readily understandable example of an ABM: the Schelling segregation model.

There are some similarities between DSGEs and ABMs. Both types of models are run using computer programs that have defined inputs that can be chosen by the person running the model. An example of one input might be the value of one firm or sector's initial capital (which can be changed by typing in a number) that will affect how many goods it can produce. After every run, the model will provide specific outputs such as a number that represents the goods produced by that sector, or the Gross Domestic Product (GDP) of the economy as represented by the model as a whole. To start either model, one would open the program and set the values of the relevant variables, then set the model to run. In this way, the outputs of different runs can be compared. For example, one might first start by typing in a low value for the initial capital of one type of firm, and then check the GDP that is output by the model. Then, for the next run, a high value of industrial input might be chosen, and the model run yet again, after which the second GDP output can be compared to the first GDP. In this way, it is possible to theorize how a change in the input (initial capital) affected output (GDP).

However, even with the same inputs, a model might give different values for the outputs after different runs, so usually the model is run numerous times to check for consistency. For those unfamiliar with economic models, it is perhaps easier to visualize a weather model. In such a case, the modeler would open the program interface for the model, which includes a colored map of the kind often seen in weather reports, and select a value for the inputs-prevailing winds in a particular region-then run the model numerous times to see how often, and under which circumstances, hurricane force winds (outputs) develop. In addition, the model software can be reprogrammed, within some limitations, so that new kinds of inputs (for example, temperature, rainfall) might be added, and others removed.

As indicated in Table 1, DSGE models have characteristics that both derive from, and have resulted in them being categorized as representing, machinic conceptions of economic life. For unlike most ABMs, the tendency of DSGE models is to favor stability, equilibrium, and direct causality—characteristics that traditionally have been associated with machines. 


\begin{tabular}{|l|l|}
\hline $\begin{array}{l}\text { DSGE Models } \\
\text { Dynamic Stochastic General } \\
\text { Equilibrium Model }\end{array}$ & $\begin{array}{l}\text {-machine } \\
\text {-equilibrium } \\
\text {-representative agent } \\
\text {-equations with a solution set } \\
\text {-analogous to a game of solitary chess }\end{array}$ \\
\hline $\begin{array}{l}\text { ABM Models } \\
\text { Agent Base Models }\end{array}$ & $\begin{array}{l}\text {-ecology } \\
\text {-emergence } \\
\text {-heterogeneous agents } \\
\text {-computer simulations with possible outcomes } \\
\text {-analogous to chess with millions of players }\end{array}$ \\
\hline
\end{tabular}

Indeed, the charter of the congressional hearing, discussed earlier, also criticized DSGE models for their machine-like agents, who are:

endowed with a kind of clairvoyance. Immortal, they see to the end of time and are aware of anything that might possibly ever occur, as well as the likelihood of its occurring; their decisions are always instantaneous yet never in error, and no decision depends on a previous decision or influences a subsequent decision [...] All agents of the same type-that is, individuals or firmshave identical needs and identical tastes (Subcommittee on Oversight 2010,4).

Crucially, Gallegati and Kirman (2015) note two further consequences of this assumption of rationality: the difficulty of integrating either money or time: "The very absence of money and credit is a consequence of the fact that in GE [general equilibrium] there is complete information and rationality, i.e. there is no time."

Defenders of the DSGE approach are quick to point out that DSGE models have already altered significantly from what could be considered a conventional approach, thus perhaps also mitigating the extent to which they function like purely rational, clockwork-oriented machines. Two major differences from previous models are included in the name "DSGE." The "DS" refers to "Dynamic Stochastical," which was added to the original "GE" or "General Equilibrium" model. If general equilibrium represents the hardline approach that assumes that economies always find one stable equilibrium, then allowing the model to be dynamic implies that the system can evolve; and to be stochastic means that there are at least some limited elements of randomness. Both these factors indicate that DSGE models are less predictable and stable, and more like observed economic data. Speaking in favor of revising and using DSGE models, in combination with other methods, the economist Mark Thoma notes that DSGE modelers are now focused more on crisis scenarios, and so they will be "much more prepared if history repeats itself"(2015). 
Microfoundations are one quality that both DSGE models and ABMs share. This means that, rather than modeling the economy as a black box with little internal differentiation, the overall state of the system is built up through the interactions of individual agents. ${ }^{10}$ As such, both model forms also have an internal structure, with the related character that agents are divided into different types-for example, of "individuals or firms." This emphasis on microfoundations and internal structure is partly a result of the highly influential Lucas Critique (Lucas 1976), which heavily criticized modelers who only searched for patterns in highly aggregated historical data without allowing for internal differentiation."

Yet, here the overall similarities of ABMs and DSGEs end due to two prominent differences. First, ABMs assume more heterogeneous agents than DSGEs. As noted above, DSGE models typically assume that all agents of the same type (such as firms) have the same "needs and tastes," so that overall diversity is highly reduced. In contrast, ABMs work with heterogeneous agents. Heterogeneous agents are both those who both have different types of agents and those who can differ even within agent types. So, each individual agent can have unique preferences, and preferences and strategies can evolve over time as agents respond to the changing system.

The role of diversity is related to the ability to provide an ultimate solution for the model, given particular starting parameters. A DSGE model can usually be summarized as a set of equations, and these equations offer at least the possibility of a solution or set of solutions. Implicit in the notion of a machine is that there is at least one way for it to "work" correctly, i.e. to solve the problem that it was designed to answer. Modelers can choose different initial conditions (plug in different variables) to these equations and find the output of the model for those conditions. In contrast, ABMs require a spatial component, usually a grid (as in the Schelling model discussed below), or a network. The solution of an ABM, to the extent that there is one, is not singular. More often, the output is taken to be a series of graphs or images of a range of the final states of the agents in that grid or network (see Figure 2 for a similar precursor). However, to date it has been difficult to calibrate such "stylized facts" to the empirical facts of the market (Delli Gatti 2012).

Second, DSGE models opt for a focus on an economy that is in equilibrium, even though they allow that external and unpredictable shocks or crises might occur, particularly in the Real Business Cycle model. Further, frictions can be incorporated into DSGEs to make them more "realistic," but these frictions tend to act more as a limitation or drag on the model than as an integral component of it. This contrasts with ABMs, which allow the state of the economy to arise entirely from the changing and sensitive interactions among the agents. That means that a wellfunctioning economy can end up in a crisis without any shock from outside (Mandelbrot and Hudson 2010). Thus, ABMs are intended to offer an alternative approach (Testimony of Scott E. Page, Subcommittee on Oversight 2010) that goes far further than DSGEs in correcting for how complicated and unpredictable the economy can be even in the absence of outside shocks.

${ }^{10}$ For brief accounts of recent debates over how "micro" microfoundations might be, see Davies (2015) and Krugman (2013).

"For a critique of the Lucas critique from a complexity perspective, see Delli Gatti et al. (2010). 


\section{Schelling's Segregation Model: Heterogeneous Equilibriums}

To better understand the relationship between ABMs and DSGEs, it is helpful to look more closely at an iconic precursor of ABMs (Sethi 2015): the Schelling Segregation model. It requires no mathematical background, and it is simple enough to briefly illustrate the ecological approach of agent-based modeling, as well as some of the major concerns and possibilities moving forward. Thomas Schelling, a sociologist and a Nobel laureate in economics, devised his segregation model on paper (1971), using a system of circles and number signs (Figure 2).

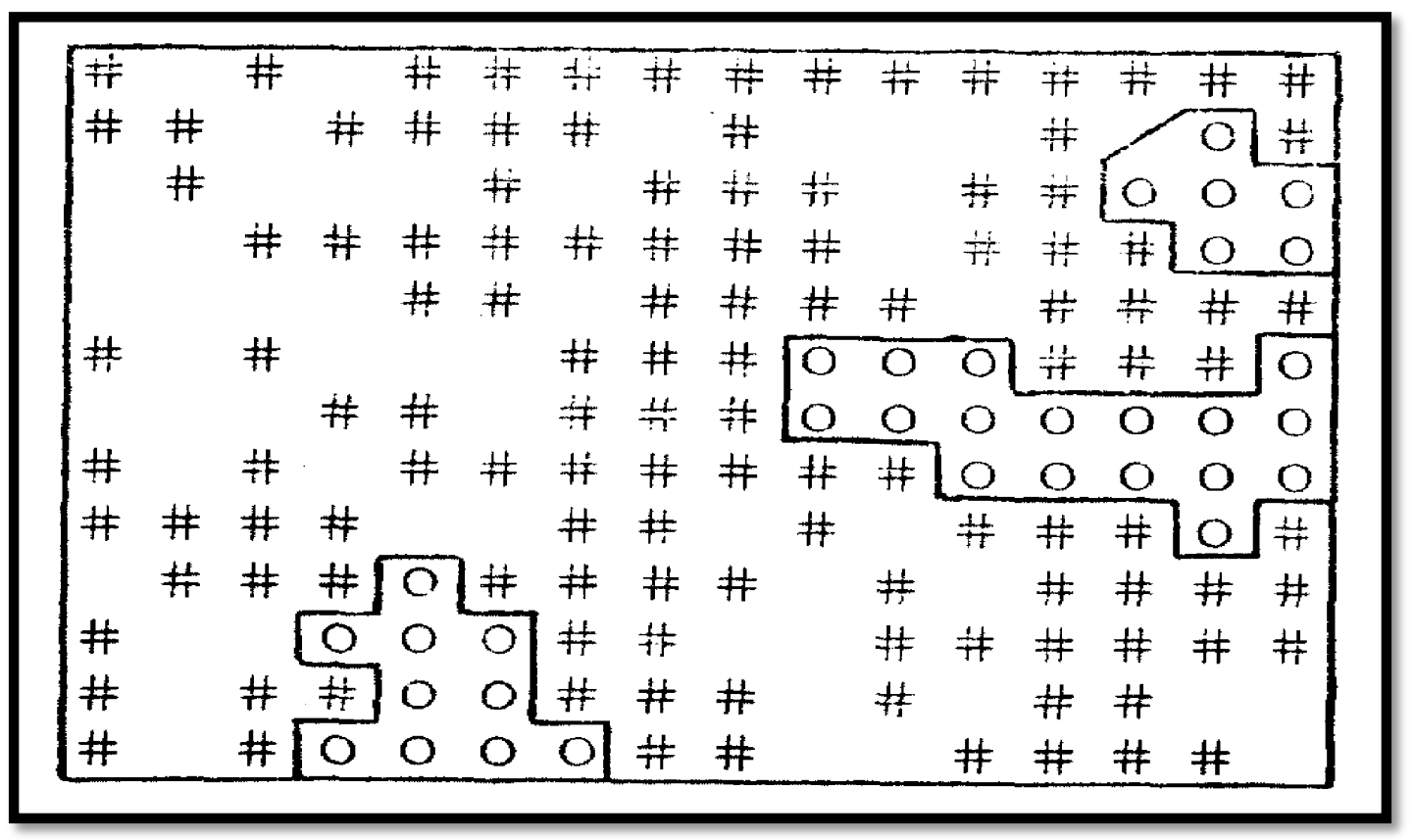

Figure 2. An exemplary visualization of the Schelling Segregation Model. The two types of agents are circles and number signs. They cluster into segregated neighborhoods despite each dot having only a slight preference for living among dots of the same type as itself. The neighborhood boundaries were added for clarity only. Source: Schelling 1971, 164.

The Schelling model demonstrates how macro-level processes, for example segregation as illustrated in Figure 2, can emerge from small micro-level preferences. Schelling allows that the model only describes subtler dynamics of segregation rather than explicit discrimination, and that it might apply to many forms of segregation including by race and economic class in the US (Schelling 1971).

In the model, there are two "types" of agents, and each has a slight preference for living among others that are the same type as themselves. In Figure 2, one type of agent is represented by circles, and another by pound signs (or number signs). The model begins with a random assignment of agents, one per square of the grid. Then, as it runs, all the agents consider their 
own positions, including the colors of their neighbors, and will move to a new square closer to others of the same color if they feel outnumbered. Once every agent has moved or stayed, then that "turn" ends and a new turn begins, with the agents considering their new neighborhoods. The strength of the preference is one parameter that can be changed by the modeler to see what different outcomes will result. By running the model even through a few dozen iterations, Schelling's model can show how in the long run even minimal preferences for one's in-group can lead to overall segregation across the grid. Different neighborhoods (areas of one concentrated color or symbol) arise solely from the agents' movements according to their individual preferences.

The Schelling model illustrates the contrast between ABMs and DSGEs. As noted, both $\mathrm{ABMs}$ and DSGEs are usually run through computer programs, software interfaces that allow the user to select values for inputs and then see how initial values affect the outputs of the model However, a DSGE model operates according to a set of equations and, for output, might provide traditional trend graphs or tables of numbers. In contrast, the output to an ABM would appear more like Figure 2, albeit with different colors in place of symbols. In the Schelling model, a user might input a specific preference, such as a number indicating how strongly each type of agent prefers to self-segregate. For example, for one agent (the pound signs) a preference of " 0 " might mean that an agent will move only if none of their immediate neighbors are of their own type, whereas a preference of " 7 " might mean that the agent will move even if only one of their neighbors is of a different type than their own. The "output" is a colored grid and the modeler's own observations of how fast the initially random distribution of agents forms into fully segregated neighborhoods of a single symbol or color. Thus, in the Schelling model, segregated neighborhoods are said to emerge through the preferences and movements of individual types of agents."

The presence of fundamentally different types of agents in an ABM model (i.e. two different symbols or colors) can distinguish it from the DSGE model, where there are a limited number (and not infrequently only one) of types of representative agents. In ABMs, all of the different types of agents are integral to the workings of the model. So for example, in the Schelling model, the inputs can be set such that one type of agent (e.g. circles) would have no tendency to self-segregate, whereas a second type (pound signs) would have a high tendency to self-segregate. The outcomes will differ greatly if both types of agents are set to strongly selfsegregate. This interaction among different types of agents is fundamental to the technical workings of ABMs, and it contrasts intrinsically with DSGEs. In DSGE models, the model is a set of equations that describe the actions of one type of representative agent. The equations are simply so complicated that they are run on a computer, but in theory they could be calculated by hand. But for ABMs, no set of equations exist that might fully describe what happens as the

12 A simple video of the Schelling model's output as it runs is available here, accessed April 16, 2016: https:// www.youtube.com/watch?v=dnffIS2EJ30. Additional explanation of how the model works, in the form of an online lecture by noted theorist of complexity and society, Scott E. Page, is available here, accessed April 16, 2016: https: / / www.youtube.com/watch?v=dFl3Cfw12bo. 
model is run. The "equations" are the program itself. Even when the model is done by hand, as in Figure 2, the modeler must use a grid.

The Schelling model embodies both the positive potentials and pitfalls of ABMs. In terms of pitfalls, the model fails to account for the absence of imbalances of power, since all agents can move equally. Similarly, although there have been calls within complexity theory to "take into account the different nature of atoms and agents" (Gallegati and Kirman 2015), ABM model agents are, to some extent, treated as separable atoms. Thus, each agent belongs to either the first or the second group, leaving no room for agents who might belong to both groups, or groups not present in the model, or to no group at all. These account for only a small number of the potential pitfalls, and many of these are shared or exacerbated in DSGE models. In contrast, to see their positive potential, and their qualitative difference to DSGEs, it is helpful to compare ABM models to games of chess. ${ }^{.1}$ In this case, DSGE models would be like playing chess against oneself, with one person moving for black and white, in turn. In contrast, ABM models would be like playing a game of chess with potentially millions of players, and where the rules kept changing with every turn.

\section{EURACE: An Ecosystem of Miniscule Machines}

Much like the turn to complexity in biology was based on the idea that, as Robert Rosen notes, "the machine metaphor is not just a little bit wrong; it is entirely wrong and must be discarded" (Rosen 1991, 23), complexity models in macroeconomics intend to break free from machine models. And yet, we contend that a cyborg conglomeration of machine and ecology might be what in fact arises in complexity models. This raises the question: how might such cyborgs enable specific accounts of social and economic life, while foreclosing others? This section addresses this question by focusing on a recent model that combines characteristics of machine and ecology conceptions.

In contrast to the more common small-scale and highly stylized models, the EURACE model is considered a policy-relevant $\mathrm{ABM}$ in that it is designed to be large and heterogeneous enough to mimic real-world policy scenarios. As an ABM, it is fully situated within the complexity (ecology) approach. However, closer examination reveals that despite being an ecology model EURACE in fact already combines distinct elements of both ecology and machine. Because of its focus on practical predictions adapted to a "real" economy, EURACE is also a relatively new type of $\mathrm{ABM}$. Until recently, $\mathrm{ABMs}$ remained a more theoretical than practical innovation in economics, but currently there are ongoing efforts to adapt $\mathrm{ABMs}$ in order to compete with the DSGE models that are in everyday regulatory use.

EURACE is perhaps the largest and most prominent effort to make such a policy relevant macroeconomic model. Developed in concert with a team that includes the economist Joseph Stiglitz, EURACE stands for European Agent-Based Computational Economics, and it combines some of the policy aspects of common DSGE models with the benefits of ABMs like Schelling's

${ }^{13}$ Or more appropriately, for those so inclined, a game of Go. 
segregation model. It was active from 2006-2009 as part of a European funded sixth framework project (Cincotti, Raberto, and Teglio 2012), and it continues to be updated, first as EURACE@UNIBI and currently as Symphony, which is ongoing (Dawid et al. 2012; Project Symphony 2015). EURACE includes both financial and "real" economic markets, as well as a public sector. The model even incorporates monitoring agencies like central banks and Eurostat, the main European agency for statistics about European agencies.

EURACE, though commonly referred to as a "model," is in fact an overarching family of models (modules) that themselves might contain millions of computational models (agents). So, exploring the models' overall structure and integration is more salient than running through the sometimes abstruse details of the software and programming code. EURACE's modules are Agent-Based models, and so EURACE falls under the ecological perspective of many ABMs: it is intended to demonstrate the emergence of macroeconomic patterns from heterogeneous microeconomic agents. Nonetheless, EURACE's design also draws on machine metaphors in surprising ways. Given that ABMs have emerged (as it were) from existing models, it can be expected that a newer model might contain both ecological and machine metaphors. However, in EURACE, notions of machines are used in very specific ways. Thus, EURACE represents only one of numerous possible combinations of ecology and machine. Here we first discuss the unique amalgamation of ecological and machinic metaphors in the composition of EURACE, and then, in the conclusion, we turn to some of the other possibilities for joining the two conceptions.

\section{EURACE as an Ecological Machine}

To demonstrate how EURACE represents a particular constellation of ecology and machine, we take each metaphor in turn, beginning with how EURACE is explained through the notion of ecology. In their published work on the model, its creators explain that EURACE is a complexity model whose major constituents contain five ABMs or markets that interact with each other: labor, goods, credit, finance, and investment. The agents in these markets are heterogeneous and consist of seven major types: households, firms, banks, central banks, government, Investment Goods firms, and Eurostat (Figure 3). Agents can participate in more than one market, and each of the markets (sub-models) is developed first before being integrated into a larger framework (Cincotti, Raberto, and Teglio 2012; Deissenberg, van der Hoog, and Dawid 2008). Nonetheless, like all models, it does contain simplifications. Although designed to encompass the 28 countries of the EU, the model can be restricted to a single "a-spatial" country, government, and type of technology to simplify its implementation."

\footnotetext{
${ }^{14}$ In addition, when it is spatialized, EURACE is linked to Eurostat's NUTS-2 regions, a specific set of statistical subdivisions of the EU (Cincotti, Raberto, and Teglio 2012, 2). It therefore suffers the same benefits and pitfalls of the construction of those (or indeed any) bounded statistical regions.
} 


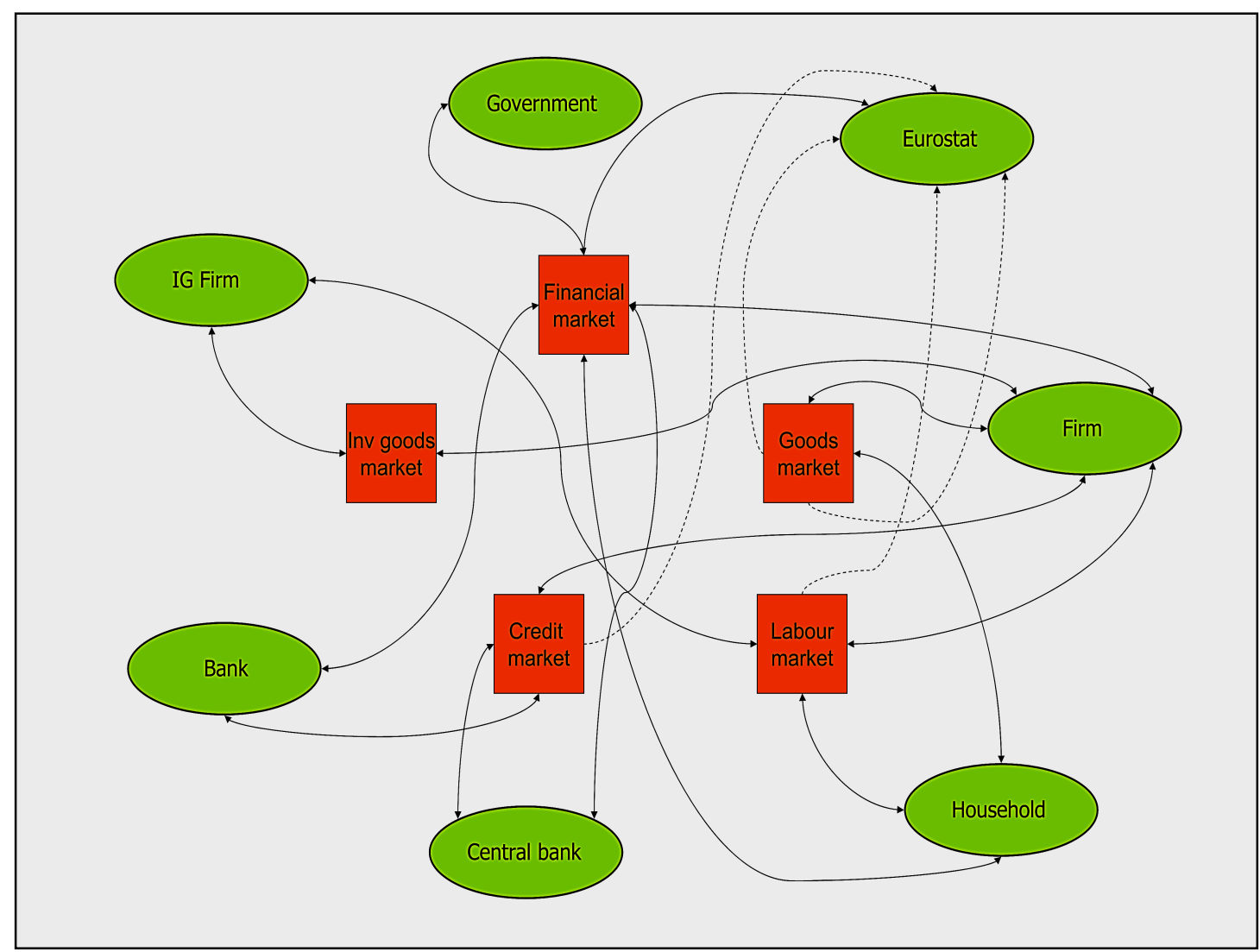

Figure 3. A diagram demonstrating the structure of the EURACE complexity model of the EU economy. The squares represent agent-based models, and the circles represent the agents who participate in those models. Source: (Cincotti, Raberto, and Teglio 2012, 5).

EURACE is a multi-layered combination of models that draws thoroughly on conceptions of emergence and related notions of ecology that incorporate communication, evolution, change, and emergence. Thus, rather than having fixed components, as many DSGE models do, the agents in EURACE are linked through series of networks that, like agent preferences, can "evolve" in order to adapt to a "changing economic environment" (Cincotti, Raberto, and Teglio 2012). Cincotti et al. $(2012,25)$ suggest that their initial tests demonstrated that it was possible to explain the emergence of business cycles, of booms and crashes, without assuming, as DSGE models would, that the economy naturally rests at some equilibrium and only crashes due to some outside shock. So, at least according to its creators, EURACE fulfills the potential for ABMs to encompass equilibrium without including it as a necessary assumption of the model. This would make it intrinsically more applicable to the study of economic crises than more traditional models. 
In addition to this ecological frame, however, EURACE also draws on metaphors of machines in relation to issues of scale, particularly the micro-scale, which Haraway also notes (2000). For if the markets in EURACE are ABMS, the agents that participate in those markets, for example the households and firms of different types, are themselves machines. They are not physical machines in the way that the MONIAC is. Nonetheless, they are literally called "machines" in the literature. This is because they are founded on similar principles of fixed, integrated parts that add up to a whole and have a set of fixed mechanistic outputs for a set of determined mechanistic inputs. In contrast to descriptions of organisms, where an organism is said to emerge unexpectedly as something that is greater than the sum of its parts, for each individual agent within EURACE the whole agent adds up precisely to the sum of its parts by design. Yet the markets in EURACE do emerge "organically" from the non-deterministic interactions of these constituent, machinic, parts. In this sense, a reductionism ultimately underpins the emergent features of the model. But this is not a mechanistic version of reductionist emergence. In fact, EURACE can be productively explained as both machine and organism. Its broader ecological behavior (a market, for example) is believed to emerge from the interaction of finer scale individuals (agents) that themselves are classified and conceptualized as machines by the modelers who use them.

To better understand why the agents are considered to be machines, it is necessary to delve deeper into EURACE and the composition of its agents. EURACE is constructed using the FLAME (Flexible Large-Scale Agent-Based Modeling Environment) framework that helps make comparable a variety of economic and ecological models (Cincotti, Raberto, and Teglio 2010). Nonetheless, the agents in FLAME consist of computational automata that are known as "stream X-machines." Computational automata are widely used in program design in computer science. Stream X-machines are one type of finite-state automata that consist of a specific form of a computer program, or a model of a program, that is explicitly designed to function as a computational machine. Stream $\mathrm{X}$-machines are small programs that have an input, a simple memory, and an output. The programmer can decide what Stream X-machines do with the input, and the machines are capable of learning (changing what they do) over time, depending on the inputs they receive and the state of their memory. For example, in the Schelling segregation model described in the above, the agents might be thought of as stream x-machines. Each agent has an input (the number and type of its neighbors), a memory (its preference for living with neighbors of a similar type), and an output (to move or stay put, depending on whether its neighbors fit its preference). This machinic character is reminiscent of an equilibrium approach. Thus, a NOVA documentary on economic modeling explains that one hallmark of neoclassical economics, the Efficient Markets Hypothesis, depicts financial markets as a rational enterprise that operates like one "giant calculating machine" (NOVA 2010).

However, EURACE is more intricate than a simple association with neoclassical economics might suggest. EURACE is emblematic of both the imagination of ecology-a school of fish or murmuration of starlings--and machine, with large markets involving the interactions of numerous (digital) automata whose primary means of operation is based on fixed notions of step-by-step calculation. This is why we contend that the EURACE modelers have designed what 
we are calling an ecological machine. In EURACE's case, it consists of a complex, evolving ecosystem where participants form rich networks, communicating and learning as they go along, and yet where those participants themselves are computational machines. These aspects of the model are distinct at different scales, with the agent machines operating at the micro-scale, and the ecological patterns emerging at a broader scale through their interactions. It can thus be considered a cyborg that incorporates distinct ecological (broader scale) and machinic (finer scale) components. We conclude by exploring the intricacies of this cyborg character in more detail.

\section{Conclusion: Modeler Cyborgs and their Practical Implications}

Modeling is an integral part of global economic life. Models are used to set policy and to assess economic systems. Models thus perform (MacKenzie 2006) particular conceptions of the economy and, by extension, the world. These conceptions include both implicit and explicit claims about what the economy is, what it's for, and what it should be. While it has not been our goal here to describe the performative effects of DSGE and ABM models, our analysis bears relevance for approaches that do. For we argue that if modelers' imaginaries help to shape the ways that economies are conceived, then they are likely to have effects on how economies are managed and performed. For example, some models are geared towards assessing economic stability. Alternately, a model might focus on reducing income disparities. These two goals, and the models that are used to reach them, may or may not align. Therefore, the shift from machine to ecology in modelers' discourse and practice can potentially have significant effects on the ways markets and economies are run. Hence it is important to consider shifts in the organizing metaphors of macroeconomic models. The shift we have traced here is largely from machine to ecology, but, as we argue, recent developments are in fact, pace the emic accounts of modelers themselves, best understood as combining machinic and ecological elements.

There are several implications of our contention that it is productive to conceive of EURACE as an ecological machine. Together, we argue in this conclusion, these implications indicate how social theory and the role of alternative imaginations might help to open up both notions of complexity (e.g. Law and Mol 2002) and, perhaps moreso, ABMs themselves. For many complicated and possibly unquantifiable aspects of society, economy, ecology, and machine are left out of models as they now stand. Indeed, despite the nuances of complexity models and the ways they improve upon existing frameworks, there remains a certain reductionism in claiming, as many complexity modelers do, that they are holistic images of either ecological or social systems (Sawyer 2005).

For, although complexity models are perhaps more open than the extreme oversimplifications of DSGEs, there is still much room for improvement. Social reductivism continues to plague the literature on ABMs. To give one example of many, speaking of EURACE's "purposive agents," Deissenberg et al. claim that they "Move around the landscape, communicate with other agents, work, consume, learn, invest, speculate on financial markets, that is, that potentially conduct all human activities of interest" (2008, 541, emphasis added). But this should give us pause: are moving, communicating, consuming, learning, investing and 
speculating actually all human activities of interest for the model? This raises the related question: are emergence and calculation (the transformation of an input into an output) all of the possible interpretations of ecology and machines? How would it be possible to know if they were all of the possibilities, and who would decide?

Donna Haraway's conception of the cyborg provides one answer to such claims that either society or technology could ever be fixed, fully knowable, or all-encompassing. While Philip Mirowski notes that "'complexity' is the cyborg trademark par excellence" (2002, 93), Haraway's cyborg notion both uses and implodes dichotomies between machines and organisms (and by extension, ecosystems). Through the cyborg, Haraway advocates for the creation of beings (and by extension, models) that are both human and nonhuman, technical and natural. Here, then, can the social sciences more broadly contribute a metaphor that overcomes the current, ultimately false dichotomy between machine and ecology? What would economics look like if modeling operated from a conception of the cyborg as a central organizing imaginary?

As Jackie Orr (2012) has noted, Haraway's conception of the cyborg is as much about imagination as materiality. Indeed, Haraway herself states that a cyborg is "a hybrid of machine and organism, a creature of social reality as well as a creature of fiction" $(2000,291)$. Haraway was writing in the 1980s, at a time when some subgroups within feminism and social theory were concerned about the spread of science and technology and their use in the control of daily life.

Haraway argues against the idea that the best response to technology's dangers is to place increasing, and selective, value upon nature, and to depict nature as a sphere that is separate from, and opposed to, technology. With both positive and negative implications, the sphere of nature was traditionally assigned to women, often women of color, who were (stereotypically) believed to be more natural, emotional, and caring. In this context, idealized depictions of nature as somehow better and opposed to technology are difficult to avoid. Yet Haraway sought to combine nature and technology to a point where the distinction between them no longer seemed so "natural," while also avoiding implicitly attributing liberatory or domineering characteristics to either.

Haraway's work implicitly draws on critiques of notions like ecology, as analyzed here. It is also instructive for the imaginations of modelers and their interpretations moving forward. For, even though complexity modelers fully embrace technology, they nonetheless exhibit a sort of romantic naturalism both by drawing on claims that ecology is somehow more natural, fitting, or better for the study of economic life, and by opposing ecology to the supposedly cold and impersonal machine-like models. In contrast we argue that the underpinnings of current efforts in macroeconomic complexity modeling are better understood, not when machine and ecology aren't pitted against one another, but when the cyborg qualities of complexity models are brought to light. Instead of espousing nostalgia for ecologies or more conventionally favoring mechanistic (DSGE) approaches, the embrace of a cyborg imaginary is not only a more accurate description of current modeling efforts, but it also potentially opens up the possibility for models to reflect a more variegated array of social relations and conceptions of what the world is or should be. A "cyborg" model thus allows us to recast the dominant metaphors that are used to describe models' relationships with the world. 
To give just one, necessarily tentative example here: cyborg models might allow for a reimagining of the boundaries between the model and its modelers. We now briefly explore this example in order to explain why such a reimagining can be advisable or beneficial in terms of allowing for more varied macroeconomic models. Discussions of models are often restricted to the computer software and hardware that allow models to be run. In contrast, a cyborg conception of modeling would allow for the modelers to be included in the notion of the model itself. Many modelers aim to maintain a distance between modeler and model, as well as between models and a reality that the model supposedly reflects (Atlan 2011). In this conception, models function more as thought experiments than representations of reality. In contrast, Haraway argues that cyborgs are best studied as part of the broader contexts in which they participate. Thus, if macro patterns are said to emerge from micro agents, models might be said to arise from complicated conglomerations of their social and technical aspects. As such, it is necessary to include the modelers as well as the institutions and societies that they draw on, and help reproduce, in their conceptions of a model and its significance.

So, instead of seeing models as simulations that happen within a computer program or an array of programs, Haraway opens up the possibility to conceive of a collective cyborg that includes both models and modelers as aspects that are interrelated in unexpected ways. Such an awareness enables analysis of the social-material configurations that make models like EURACE possible, including the networks of academics, the EU funding and its framing, and the relationship with financial agents themselves-all of which can be formative in terms of a model's focus, form, content, as well as the ways that its results are conceived and explained. So a cyborg conception of modeling includes modelers within the definition of a model. In doing so it helps to acknowledge the power of broader conceptions of society, economy, human, nature and machine and ecology, while at the same time allowing for their use and potential transformation.

In addition to the example just discussed, the notion of the cyborg also draws attention to the fact that the ways agents are defined, the ways that varying components interact, and the notions of machine or ecology they invoke, is not predetermined. It thus invites critical analyses of the definitions of agents, components, and their interactions. Such an analyses are central to qualitative research on the performative role that models play in social and material worlds (MacKenzie 2006), and vice versa..$^{5}$ In its concern for conglomerations of machines and organisms, its foregrounding of material as well as imagination, Haraway's cyborg is especially relevant for models because it moves beyond restrictive notions of individual agents, thereby also permitting more heterogeneous types of agents than those in the models we have discussed here. By allowing for notions of agents to be less rigidly defined, the cyborg provides the ability to both discern and expand upon specific legacies of the history of technology and nature, and the material configurations they entail, without either accepting or rejecting them in their entirety.

We argue that, though tentative, this kind of analysis that builds on an understanding of the organizing metaphors of models has potential political and conceptual implications in the

${ }_{15}$ They also enable a more textured understanding of the relationships between models and simulations (Kouw 2012; Mitchell 2002; M. S. Morgan and Boumans 2004). 
debate over how and when macroeconomic models work well. One concrete implication of redefining models is the issue of regulatory capture. Regulatory capture-the merging of regulators with the institutions they are supposed to regulate-has long been a concern in regulatory circles (for a legal perspective, see Levine and Forrence 1990). It continues to alarm those who seek to head off the ongoing financial crisis. Even as national governments attempt to monitor and control financial flows, they routinely invest in the markets that those flows help to create. There is a revolving door of individuals who move from regulatory bodies into financial institutions that are the subject of regulation, and back again (e.g. Graham 2015).

Regulatory capture might seem remote from run-of-the-mill macroeconomic models, but it's not. Obviously, not all modelers are subject to regulatory capture; but if regulatory capture is real, then it should have real consequences for the models regulators use. Indeed, issues of systemic, if not direct, regulatory capture may be one possible reason why DSGE models did not do so well in the run-up to the crisis. For, as Stefan Helmreich has noted in his research at the renowned Santa Fe Institute (SFI), an international hub of prominent complexity theorists: "The privileged objects of study in SFI economics—stock markets and firms-are familiar to many SFI scientists from their own experience" (2000, 175-76) trading stocks as members of the very markets they seek to describe and, in some cases, criticize. So modelers themselves come from and work within financial circles, including owning financial instruments that benefit from predictions that the stock market will only improve. As a result, even with the best of motivations, potential conflicts of interest are legion and need to be accounted for at multiple, including systemic, scales.

On their own, neither notion--machine or ecology-would allow for including concerns like regulatory capture within a modeling framework. Yet in combination, by thinking of models as ecological machines, it might be possible to produce models that are able to address the systemic issues like regulatory capture that made the recent crisis possible. Ecologically, they allow for a redefinition of models themselves, an expansion of the definition to a broader scale that also includes modelers who may or may not have an interest, due to regulatory capture, in presenting the economy a certain way. As machines, they would incorporate an awareness of the potential for modelers and other financial actors to "game the system," as happened during the crisis by manipulating its predictable, deterministic, effects. Yet only in combination are the two fully effective: including modelers and their imaginaries in discussions about models, while also acknowledging that they may have the potential to profit from economies that have been designed as "predictable" machines.

Thus, the notion of ecological machines involves neither romanticizing organicism through ecology, nor pretending that economies are ordered and predictable machines. Similarly, it does not advocate discarding legacies or imaginaries that still have much to offer in the way of understanding the world. Instead, it represents a practiced and engaged effort to refashion the histories of the under-acknowledged imaginaries, like ecology and machines, that inform modeling and economies more broadly. 


\section{References}

Agar, M. 2005. "Agents in Living Color: Towards Emic Agent-Based Models." Journal of Artificial Societies and Social Simulation 8 (1): n.p.

Arthur, W. B. 2013. “Complexity Economics: A Different Framework for Economic Thought.” Santa Fe Institute (SFI) Working Paper. http:/ / www.santafe.edu/media/ workingpapers/ 13-04-012.pdf.

Atlan, H. 2011. Qu'est-ce qu'un modèle ? Paris: Manucius.

Ballot, G., A. Mandel, and A. Vignes. 2014. “Agent-Based Modeling and Economic Theory: Where Do We Stand?" Journal of Economic Interaction and Coordination, 1-23.

Barrett, L. 2015. "Why Brains Are Not Computers, Why Behaviorism Is Not Satanism, and Why Dolphins Are Not Aquatic Apes." The Behavior Analyst, November, 1-15.

Beinhocker, E. D. 2006. The Origin of Wealth: Evolution, Complexity, and the Radical Remaking of Economics. Cambridge, MA: Harvard Business Press.

Bertalanffy, L. 1968. General System Theory: Foundations, Development, Applications. New York: G. Braziller.

Boumans, M. 1997. "Lucas and Artificial Worlds." History of Political Economy 29 (Supplement): 63-90.

——. 2012. "Visualisations for Understanding Complex Economic Systems." In Ways of Thinking, Ways of Seeing, edited by Chris Bissell and Chris Dillon, 145-65. Berlin: Springer. http:/ / link.springer.com/ chapter/10.1007/978-3-642-25209-9_7.

Bramwell, A. 1989. Ecology in the 20th Century: A History. New Haven: Yale University Press.

Buchanan, M. 2009. "Meltdown Modeling: Could Agent-Based Computer Models Prevent Another Financial Crisis?"." Nature 460: 680-82.

Caldararo, N. L. 2014. The Anthropology of Complex Economic Systems: Inequality, Stability, and Cycles of Crisis. Lanham, MD: Lexington Books.

Church, A. H. and J. Waclawski. 1998. Designing and Using Organizational Surveys. Hampshire, UK: Gower.

Cincotti, S., M. Raberto, and A. Teglio. 2010. “Credit Money and Macroeconomic Instability in the Agent-Based Model and Simulator Eurace." Social Science Research Network Scholarly Paper. Rochester. http: / / papers.ssrn.com/ abstract=1753514.

—_ 2012. "The Eurace Macroeconomic Model and Simulator." In Agent-Based Dynamics, Norms, and Corporate Governance. The Proceedings of the 16th World Congress of the International Economic Association. Vol. 2. London: Palgrave. http://www.ieaworld.org/ docs / 1042.pdf.

Cogliano, J. F. and X. Jiang. 2014. “Agent-Based Computational Economics: Simulation Tools for Heterodox Research." Handbook of Research Methods and Applications in Heterodox Economics. Edward Elgar, Cheltenham. https: / / www.aeaweb.org/aea/2014conference/program/retrieve.php?pdfid=897.

Darwin, C. 1968. The Origin Of Species. New York: Penguin. 
Davies, D. 2015. “'Microfoundations' Ain't so Microfounded." Medium: Bull Market. Accessed May 11. https://medium.com/bull-market/microfoundations-aint-so-microfounded315b46775432.

Dawid, H., S. Gemkow, P. Harting, S. Van der Hoog, and M. Neugart. 2012. “The Eurace@Unibi Model: An Agent-Based Macroeconomic Model for Economic Policy Analysis." Social Science Research Network Scholarly Paper. Rochester. http:/ / papers.ssrn.com/ abstract=2408969.

Deissenberg, C., S. van der Hoog, and H. Dawid. 2008. "EURACE: A Massively Parallel AgentBased Model of the European Economy." Applied Mathematics and Computation, Special Issue on New Approaches in Dynamic Optimization to Assessment of Economic and Environmental Systems, 204 (2): 541-52.

Delli Gatti, D. 2012. "Comments on the Paper 'Macroceonomic Policy in DSGE and Agent-Based Models.'" In Agent-Based Models and Economic Policy, edited by Jean-Luc Gaffard and Mauro Napoletano, 124:15-16. Paris: French Economic Observatory (OFCE) Review, Debates and Policies.

Delli Gatti, D., E. Gaffeo, and M. Gallegati. 2010. “Complex Agent-Based Macroeconomics: A Manifesto for a New Paradigm." Journal of Economic Interaction and Coordination 5 (2): 11135.

Dijksterhuis, E. J. 1975. De Mechanisering Van Het Wereldbeeld. Amsterdam: Meulenhoff.

Evans, R. 2002. Macroeconomic Forecasting: A Sociological Appraisal. Routledge.

Farmer, J. D. and D. Foley. 2009. "The Economy Needs Agent-Based Modelling." Nature 460 (7256): 685-86.

Gallegati, M.. and A. Kirman. 2015. "Reconstructing Economics: Agent Based Models and Complexity." The Institute for New Economic Thinking. Accessed March 11. http:/ / ineteconomics.org/ uploads/ papers/gallegati-mauro-berlin-paper.pdf.

Graeber, D. 2012. Debt: The First 5,000 Years. Brooklyn: Melville House.

Graham, D. A. 2015. "Ben Bernanke Isn't the Problem, the System Is the Problem." The Atlantic. April 16. http://www.theatlantic.com/business/archive/2015/04/ben-bernanke-isntthe-problem-the-system-is-the-problem/390669/.

De Grauwe, P. 2010. "The Scientific Foundation of Dynamic Stochastic General Equilibrium (DSGE) Models." Public Choice 144 (3-4): 413-43.

Haeckel, E. 1866. Generelle Morphologie Der Organismen. Allgemeine Grundzüge Der Organischen Formen-Wissenschaft, Mechanisch Begründet Durch Die Von Charles Darwin Reformirte Descendenztheorie. Berlin: G. Reimer.

http:/ / www.biodiversitylibrary.org/bibliography/3953.

Haraway, D. 2000. “A Cyborg Manifesto: Science, Technology, and Socialist-Feminism in the Late Twentieth Century." In The Cybercultures Reader, edited by David Bell and Barbara M. Kennedy, 291-324. New York: Routledge.

Helmreich, S.. 2000. Silicon Second Nature Culturing Artificial Life in a Digital World. Berkeley: University of California Press. 
Hendry, D. F. and G. E. Mizon. 2015. “Why DSGEs Crash during Crises.” Vox EU. Accessed May 12. http:/ / www.voxeu.org/article/why-standard-macro-models-fail-crises.

Hodges, A. 2012. Alan Turing: The Enigma. Princeton, NJ: Princeton University Press.

Holland, J. H. and S. E. Page. 2007. Complex Adaptive Systems. Princeton, NJ: Princeton University Press.

Jessop, B. and N.-L. Sum. 2010. "Cultural Political Economy: Logics of Discovery, Epistemic Fallacies, the Complexity of Emergence, and the Potential of the Cultural Turn." New Political Economy 15 (3): 445-51.

Kim, J. 1984. "Concepts of Supervenience." Philosophy and Phenomenological Research, 153-176.

Klir, G. J. 2001. Facets of Systems Science. International Federation for Systems Research International Series on Systems Science and Engineering. New York: Kluwer Academic.

Knibbe, M. 2015. “DSGE Macro Models Criticism: A Limited Round Up. Part 2: Market Fundamentalism." Real-World Economics Review Blog. April 17. https: / / rwer.wordpress.com / 2015 / 04/17/ dsgemacro-models-criticism-a-limited-roundup-part-2-market-fundamentalism/.

Knorr Cetina, K. and A. Preda, eds. 2005. The Sociology of Financial Markets. Oxford: Oxford University Press.

Kouw, M. 2012. Pragmatic Constructions: Simulation and the Vulnerability of Technological Cultures. Maastricht: Doctoral Thesis, Maastricht University.

Kramer, P., P. P. J. van den den Bosch, T. J. Mourik, M. M. G. Fase, and H. R. van Nauta Lemke. 1990. “Fysioen : Macroeconomics in Computer Graphics." Economic Modelling 7 (2): 148 60.

Krugman, P. 2013. "Microfoundations and the Parting of the Waters." Paul Krugman Blog. December 20. http:// krugman.blogs.nytimes.com/2013/12/20/microfoundations-andthe-parting-of-the-waters / .

Law, J. and A. Mol. 2002. Complexities: Social Studies of Knowledge Practices. Durham: Duke University Press.

Levine, M. E. and J. L. Forrence. 1990. "Regulatory Capture, Public Interest, and the Public Agenda: Toward a Synthesis." Journal of Law, Economics and Organization 6 (0): 167-98.

Li, X. H. 2013. "Standardization for Agent-Based Modeling in Economics." http://mpra.ub.unimuenchen.de/54284/.

Lucas, R. E. 1976. “Econometric Policy Evaluation: A Critique." Carnegie-Rochester Conference Series on Public Policy 1: 19-46.

_ 1988. "On the Mechanics of Economic Development." Journal of Monetary Economics 22 (1): 3-42. doi:10.1016/0304-3932(88)90168-7.

Maas, H., T. Mata, and J, B. Davis. 2011. "Introduction: The history of economics as a history of practice." European Journal of the History of Economic Thought 18 (5): 635-642.

MacKenzie, D. A. 2006. An Engine, Not a Camera: How Financial Models Shape Markets. Inside Technology. Cambridge, MA: MIT Press.

Mandelbrot, B. B., and Richard L. Hudson. 2010. The (Mis)Behaviour of Markets: A Fractal View of Risk, Ruin and Reward. London: Profile Books. 
Mirowski, P. 2002. Machine Dreams: Economics Becomes a Cyborg Science. Cambridge, UK: Cambridge University Press.

Mitchell, T. 2002. Rule of Experts: Egypt, Techno-Politics, Modernity. Berkeley: University of California Press.

Morgan, C. L. 1931. Emergent Evolution. The Gifford Lectures . 1922. New York: Henry Holt.

Morgan, M. S. 2012. The World in the Model: How Economists Work and Think. Cambridge, UK: Cambridge University Press.

Morgan, M. S. and M. Boumans. 2004. “The Economy as a Hydraulic Machine." In Models: The Third Dimension of Science, edited by Soraya de Chadarevian and Nick Hopwood, 369401. Stanford: Stanford University Press.

Muenzinger, K. F. 1935. "Mechanism, Vitalism and the Organismic Hypothesis." Philosophy of Science 2 (4): 518-20.

Nagel, E. 1951. "Mechanistic Explanation and Organismic Biology." Philosophy and Phenomenological Research 11 (3): 327-338.

Nicholson, M. 1970. The Environmental Revolution; a Guide for the New Masters of the World. New York: McGraw-Hill.

NOVA. 2010. Mind Over Money. Public Broadcasting System (PBS). https: / / www.youtube.com/ watch?v=jlUYwSyFLTc.

Orr, J. 2012. “Materializing a Cyborg's Manifesto." Women's Studies Quarterly 40 (1/2): 273-80.

Phelan, S. E. 2001. “What Is Complexity Science, Really?" Emergence 3 (1): 120-36.

Phillips, D. C. 1970. "Organicism in the Late Nineteenth and Early Twentieth Centuries." Journal of the History of Ideas 31 (3): 413-32.

Pinch, T. and R. Swedberg. 2008. Living in a Material World: Economic Sociology Meets Science and Technology Studies. Cambridge, Mass: MIT Press.

Project Symphony. 2015. "Mission.” Symphony. Accessed May 19. http:/ / projectsymphony.eu/.

Raberto, M., A. Teglio, and S. Cincotti. 2014. "Fiscal Consolidation and Sovereign Debt Risk in Balance-Sheet Recessions: An Agent-Based Approach." In Economic Policy and the Financial Crisis, edited by Łukasz Mamica and Pasquale Tridico, 163-78. New York: Routledge.

Rosen, R. 1991. Life Itself: A Comprehensive Inquiry into the Nature, Origin, and Fabrication of Life. New York: Columbia University Press.

Sawyer, R. K. 2005. Social Emergence: Societies as Complex Systems. Cambridge, UK: Cambridge University Press.

Schelling, T. C. 1971. “Dynamic Models of Segregation.” Journal of Mathematical Sociology 1 (2): 143-186.

Sethi, R. 2015. "The Agent-Based Method." Economist's View. Accessed March 20. http:/ / economistsview.ty pepad.com/economistsview/2014/08/ the-agent-basedmethod.html.

Simpson, D. 2013. The Rediscovery of Classical Economics: Adaptation, Complexity and Growth. Cheltenham, England ; Northampton, Massachusetts: Edward Elgar Pub. 
Sommerey, C. M. 2015. “The Ghost in the Classroom: Ernst Haeckel's Rhetoric of Evolution and Its Reverberations in German Biology Textbooks, 1925-1958." Maastricht, The Netherlands: Maastricht University.

Subcommittee on Oversight. 2010. "Subcommittee on Investigations and Oversight Hearing: Building a Science of Economics for the Real World." Committee on Science, U.S. House of Representatives. https://science.house.gov/legislation/hearings/subcommitteeinvestigations-and-oversight-hearing-building-science-economics.

Tansley, A. G. 1935. "The Use and Abuse of Vegetational Concepts and Terms." Ecology 16 (3): 284-307.

Thoma, M. 2015. "In Defense of Modern Macroeconomic Theory." Economist's View. April 13. http:/ / economistsview.typepad.com/ economistsview / 2015/04/in-defense-of-modernmacroeconomic-theory.html.

Van Heur, B. 2010a. "Beyond Regulation: Towards a Cultural Political Economy of Complexity and Emergence." New Political Economy 15 (3): 421-44.

—_ 2010b. "Research and Relevance: Response to Jessop and Sum." New Political Economy 15 (3): 453-56.

Wharton, K. 2013. “The Universe Is Not a Computer.” New Scientist 217 (2903): 30-31.

Williams, R. 1982. Culture and Society 1780-1950. London: Hogart Press.

Wyatt, S. 2004. "Danger! Metaphors at Work in Economics, Geophysiology, and the Internet." Science, Technology, \& Human Values 29 (2): 242-61.

Zaloom, C. 2006. Out of the Pits: Traders and Technology from Chicago to London. Chicago: University of Chicago Press.

Zelizer, V. A. R. 1994. The Social Meaning of Money. New York: Basic Books 